\title{
Scale-up of Circulating Fluidized Bed Coal Combustors
}

\section{Technical Progress Report}

Eighth Quarter (June 1, 1990 - August 31, 1990) DOE/PC/88929--T6

by

DE91 000850

\section{Michel Yves LOUGE}

Cornell University

Sibley School of Mechanical \& Aerospace Engineering Upson Hall

Ithaca, NY 14853

Work Performed under the Grant No. DE-FG22-88PC88929

For the

U.S. Department of Energy

Pittsburgh Energy Technology Center

PO Box 10940

Pittsburgh, PA 15236

US/DOE patent clearance is not required prior to the publication of this document.

Table of contents

page

1. Introduction

2

2. Scale-up Experiments

3

3. The Role of Particle Friction

4

4. Heat Transfer Model

5

5. Next research and conclusions

6

LITERATURE REFERENCES

6 


\section{Introduction / Summary}

Circulating fluidization is a promising technology for designing efficient coal combustors with high solid feed rates. Unfortunately, limited understanding of circulating fluidized beds (CFB) renders design extrapolations from pilot reactors to full-scale plants both empirical and expensive. In particular, the behavior of large-scale units is unclear.

This experimental project has been aimed at quantifying the effects of scale-up upon the hydrodynamics of CFB coal combustors. To this end, we have constructed a cold CFB facility with the ability to recirculate -rather than discard-fluidization gas mixtures of adjustable density and viscosity. Hydrodynamic analogy between the cold bed and a coal combustor is achieved by matching all relevant dimensionless parameters (Glicksman, 1984; Louge, 1987). Several choices of gas composition and particle properties make the cold tlow analogous to that in combustors of diameters in the range 0.3 to $1 \mathrm{~m}$. Therefore, for the first time, scale-up effects are quantified directly using a single cold flow facility.

During the facility's commissioning stage, we performed the first quantitative, timedependent measurements of voidage in the wall region of the bed. The data established the presence of a dense curtain of solids falling near the wall. (Louge, Lischer \& Chang, 1990). In other experiments, we showed that, if unchecked, electrostatics has significant effects on the flow. In this regard, we have found a powerful anti-static arditive that virtually eliminates the problem.

During the previous reporting period, we carried out the first two phases of the scale-up experiments i.e., the fluidization of glass beads and plastic pellets using mixtures of helium and carbon dioxide ( $c f .7^{\text {th }}$ Quarterly Report). By comparing data obtained in these experiments, we have verified the hydrodynamic analogy predicted by the dimensional analysis. In the present reporting period, we have completed the third phase of the scale-up experiments using iron flakes. By fluidizing two glass powaers of identical characteristics but largely different surface friction coefficients, we have also discovered, to our surprise, that particle friction affects the flow.

Because particles undergo frequent collisions in the CFB, we have also devoted some effort to modelirig their interaction in gas-solid flows using elements of s apid granular flow. Because detailed measurements of velocity and velocity fluctuations are not yet available in dense flows, we have first considered dilute, turbulent flows of relatively massive particles, for which Tsuji, et al. (1984) had recently published detailed data. A numerical solution of the resulting governing equations has provided velocity and turbulent energy profiles in good agreement with the measurements of Tsuji et al. (1984), and it has 
shown that particle collisions can play an important role even under dilute conditions (Louge, Mastorakos \& Jerkins, 1990). Encouraged by these results, we have also modeled the heat transfer from a suspension of massive particles of low Biot number transported in a vertical pipe (Louge, Mohd. Yusof, \& Jenkins 1990). The present report will summarize the latest results from this heat transfer model.

\section{Scale-up Experiments}

The principle of the scale-up analogy between a generic coal combustor and our cold CFB flow facility is straightforward: in this facility, a cold-flow riser (diameter: 20 $\mathrm{cm}$, height: $7 \mathrm{~m}$ ) is fluidized with binary gas mixtures of adjustable density and viscosity (components: helium and carbon dioxide). Hydrodynamic analogy between the cold bed and a generic coal combustor is achieved by matching all relevant dimensionless parameters (Glicksman, 1984; Louge, 1987), which include solid loading $\mathrm{m}=\mathrm{G} / \rho_{\mathrm{s}} \mathrm{u}$, Froude number $\mathrm{Fr}=\mathrm{u} / \sqrt{\mathrm{gd}}$, Archimedes number $\mathrm{Ar}=\rho_{\mathrm{s}} \rho \mathrm{d}^{3} / \mu^{2}$, and density ratio $\mathrm{R}=\rho / \rho_{\mathrm{s}}$. Several choices of gas mixture composition and solid particle properties make the cold flow analogous to that in combustors of several possibie sizes. Analogous combustor diameters D are found in the range 0.3 to $1 \mathrm{~m}$. This allows direct quantification of scale-up in an environment ideal for detailed measurements. In this project, three gas-solid mixtures are fluidized to mimic the behavior of coal combustors of increasing sizes (Table 1).

Tahle 1

\begin{tabular}{|c|c|c|c|c|c|c|c|c|}
\hline \multicolumn{4}{|c|}{ Gases } & \multicolumn{4}{|c|}{ Solids } & \multirow{2}{*}{$\begin{array}{c}\text { Analogous } \\
\text { Diameter } \mathrm{D}_{0} \\
\mathrm{~m}\end{array}$} \\
\hline $\begin{array}{l}\mathrm{He} \\
\%\end{array}$ & $\begin{array}{c}\mathrm{CO}_{2} \\
\%\end{array}$ & $\begin{array}{c}\rho_{1} \\
\mathrm{~kg} / \mathrm{m}^{3}\end{array}$ & $\begin{array}{l}\mu_{1} \times 10^{5} \\
\mathrm{~kg} / \mathrm{m} \cdot \mathrm{sec}\end{array}$ & type & $\begin{array}{c}\rho_{\mathrm{s} 1} \\
\mathrm{~g} / \mathrm{cm}^{3}\end{array}$ & $\begin{array}{l}\mathrm{d}_{1} \\
\mu \mathrm{m}\end{array}$ & $\begin{array}{l}\phi d_{1} \\
\mu \mathrm{m}\end{array}$ & \\
\hline 92 & 8 & 0.30 & 2.0 & plastic grit & 1.5 & 234 & 161 & 0.32 \\
\hline 80 & 20 & 0.49 & 1.9 & glass spheres & 2.5 & 109 & 109 & 0.47 \\
\hline 29 & 71 & 1.3 & 1.6 & iron flakes & 6.6 & 67 & 49 & 1.05 \\
\hline
\end{tabular}

In this reporting period, we have completed the series of experiments with iron

flakes. With this powder we have found it more difficult to operate the facility than with the plastic and glass powders. In particular, because the analogcus combustor diameter is much larger with the iron flakes, we have observed choking at a dimensionless solid flux much lower than the corresponding value for the two previous powders. In this context, we have found that the limiting solid fluxes for different riser diameters are well predicted by the experimental correlation of Yang (1975).

In addition, we have found that the pressure gradient with iron grit is larger near the bottom region of the bed than it is with the other powders (Figure 1). This difference may be attributed to the fact that when the bed is near choking, the gas cannot entrain as much 
solids upwards. Then, because a larger amount of powder accumulates at the bottom of the riser, the pressure gradient increases in this region. Similar results were also observed by Patterson (1959).

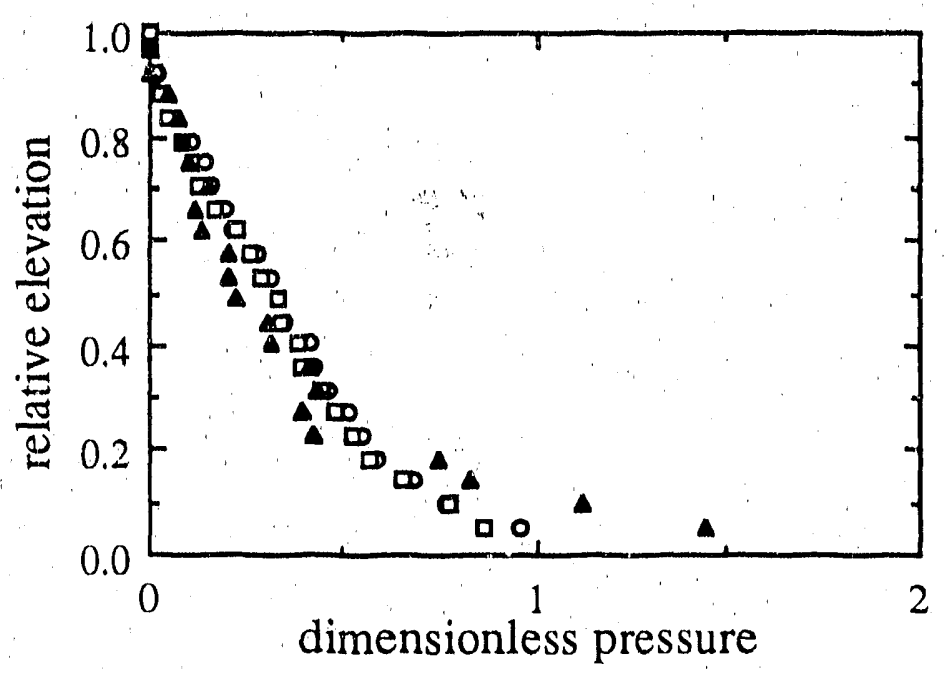

Fig 1. Vertical profiles of dimensionless pressure $\left(\mathrm{p}-\mathrm{p}_{\mathrm{top}}\right) / \rho_{\mathrm{s}} \mathrm{gD}$ vs. relative riser elevation for conditions analogous to a velocity of $8.7 \mathrm{~m} / \mathrm{sec}$ and a solid flux of $50 \mathrm{~kg} / \mathrm{m}^{2} \mathrm{sec}$ in a coal-burning CFB combustor. The open circles represent the test with plastic grit, the open squares with glass beads, and the solid triangles with iron flakes.

\section{The Role of Particle Friction}

By fluidizing two glass powders of identical characteristics but largely different surface friction coefficients, we have discovered, to our surprise, that particle friction affects the flow. One powder is the untreated spherical glass Ballotini that we have used in the scale-up experiments of Table 1. Its surface friction coefficient is high. The other powder consists of the same glass with a monolayer silicon coating that reduces the surface friction considerably. Figure 2 shows the average vertical pressure profile obtained with the two powders. The difference in overall pressure drop may be as high as a factor of two across the entire riser. Clearly, this observation has important consequences for modeling. In particular, friction introduces an additional dimensionless parameter to the list that characterizes the hydrodynamic behavior of risers. Because the dimensionless pressure profiles that we have observed for uncoated glass beads and plastic grit are identical under a wide range of conditions, we can either conclude that the surface friction coefficients of the two powders are identical or, if they are not, that they are both large enough to lie in a regime where their actual value is inconsequential. 
Because particle collisions dominate the transport of granular momentum near the wall, we believe that, by controlling the size of the falling curtain of solids, friction affects the overall voidage of the bed. We plan to test this assumption by performing detailed measurements of collision frequencies with the wall, and by comparing the results with a model of the granular mechanics of the wall region.

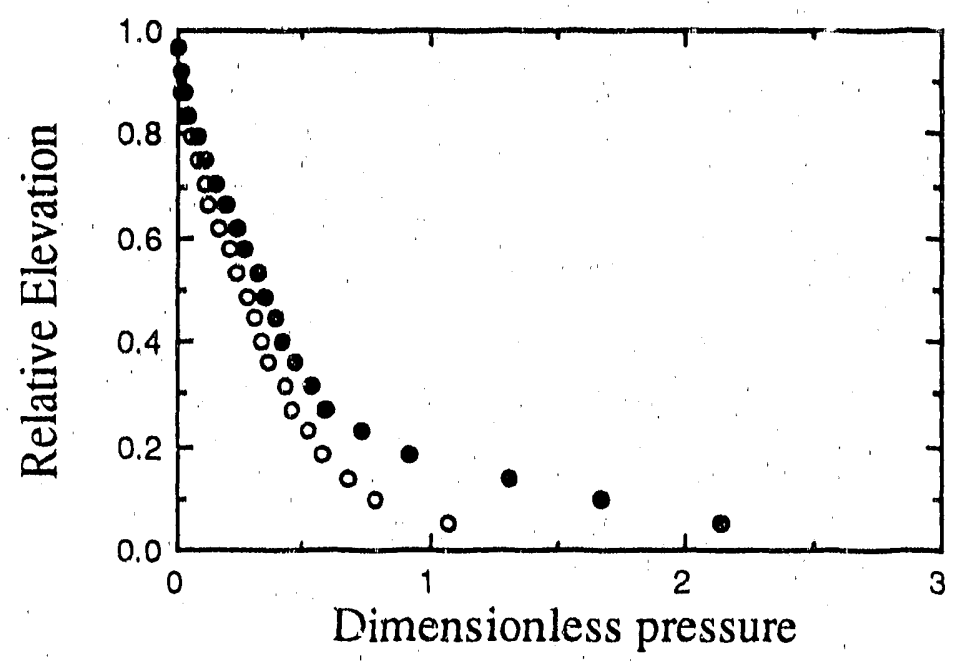

Fig. 2. Vertical profiles of dimensionless pressure $\left(\mathrm{p}-\mathrm{p}_{\mathrm{top}}\right) / \rho_{\mathrm{s}} \mathrm{gD} v \mathrm{~s}$. relative riser elevation for conditions analogous to a velocity of $6.6 \mathrm{~m} / \mathrm{sec}$ and a solid flux of $42 \mathrm{~kg} / \mathrm{m}^{2} . \mathrm{sec}$ in a coal-burning CFB combusto. The open circles represent the test with coated glass beads, and the solid circle with uncoated beads.

\section{Heat Transfer Model}

Encouraged by the results from our hydrodynamic model of pneumatic transport, we have studied the heat transfer from a suspension of massive particles of low Biot number transported in a vertical pipe. To the hydrodynamic equations used in the flow model we add two coupled heat equations for the particle and the gas phase. The exchange of heat between the two phases is calculated by averaging the heat transferred by single particles. The conductivity of the particle phase is derived from the particle self-diffusion coefficient of kinetic theory. Homogeneous boundary conditions are obtained for the temperature of the particle phase assuning negligible transfer of heat during collisions. The equations are solved numerically to predict heat transfer rates at the wall and temperature profiles across the flow (Louge, Mohd. Yusof, \& Jenkins 1990).

Results from the model have shown that, although the particles do not exchange any heat directly with the wall, their presence steepens the gas temperature gradient, which generally enhances the transfer of heat. However, for relatively small particles, this 
enhancement may not materialize at low values of the solid loading as the particles reduce the level of turbulent kinetic energy. These predictions are in good agreement with published data for this regime. We first drafted a paper describing the model for the 1989 Annual Meeting of the AIChE. We are now finishing the final version that incorporates detailed comparisons with data.

\section{Next Research and Conclusions}

During the eighth quarter of this project, we have completed a series of scale-up tests using iron flakes, we have observed unexpected effects of particle surface friction on the hydrodynamics of the CFB riser. In the next reporting period, we will reduce and compare data from all scale-up tests, write up the results and continue to investigate the role of friction.

\section{REFERENCES}

- L. Glicksman: Chem. Eng. Sci. 39, 1373 (1984),

- M. Louge: "Circulating Fluidization Research at Cornell: A Study of Hydrodynamic Scale-up Effects", Proc. 9th Int. Conf. on Fluid. Bed Comb., ASME (1987) p. 1193-97.

- M. Louge: "Scale-up of Circulating Fluidized Bed Coal Combustors", Tech. Prog. Rep., First to Seventh Quarters (Dec. 1, 1988 - May 31, 1990), Grant DE-FG22-88PC88929.

- M. Louge, D.J. Lischer \& H. Chang: "Measurements of Voidage near the Wall of a Circulating Fluidized Bed Riser", Powder Tech. 62, 267-74 (1990).

- M. Louge, E. Mastorakos \& J.T'. Jenkins: "The Role of Particle Collisions in Pneumatic Transport" J. of Fluid Mech. (April 1990), under review.

- M. Louge, J. Mohd. Yusof \& J.T. Jenkins: "A Model for Heat Transfer in the Pneumatic Transport of Large Particles", Annual Meeting of the AIChE, San Francisco, Nov, 1989.

- Patterson, R.C.: ASME J. Engineering for Powder, p.43-54 (1959).

- Tsuji, Y., Morikawa, Y. \& Shiomi, H. "LDV measurements of an air-solid two-phase flow in a vertical pipe", J. Fluid Mech. 139, $417-34$ (1984).

- Yang, W.C.: "A mathematical definition of choking phenomenon and a mathematical model for predicting choking velocity and choking voidage", AIChE J. 21, 5 pp. 1013$15 \cdot(1975)$

\section{DISCLAIMER}

\footnotetext{
This report was prepared as an account of work sponsored by an agency of the United States Government. Neither the United States Government nor any agency thereof, nor any of their employees, makes any warranty, express or implied, or assumes any legal liability or responsi bility for the accuracy, completeness, or usefulness of any information, apparatus, product, or process disclosed, or represents that its use would not infringe privately owned rights. Reference herein to any specific commercial product, process, or service by trade name, trademark, manufaciurer, or otherwise does not necessarily constitute or imply its endorsenent, recommendation, or fuvoring by the United States Government or any agency thereof. The views and opinions of authors expressed herein dn not necessarily state or reflect those of the United Siates Government or any agency thereof.
} 

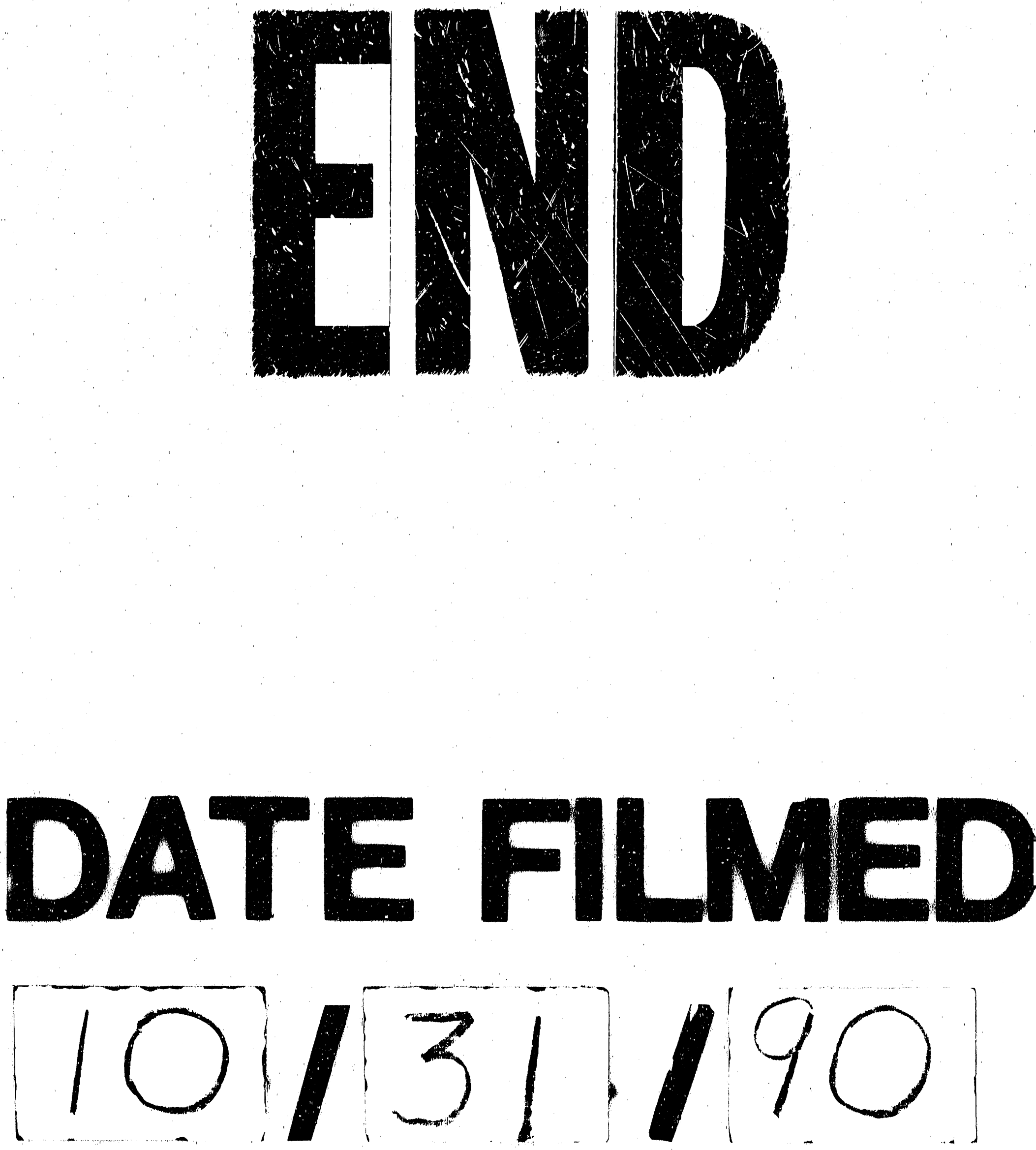
